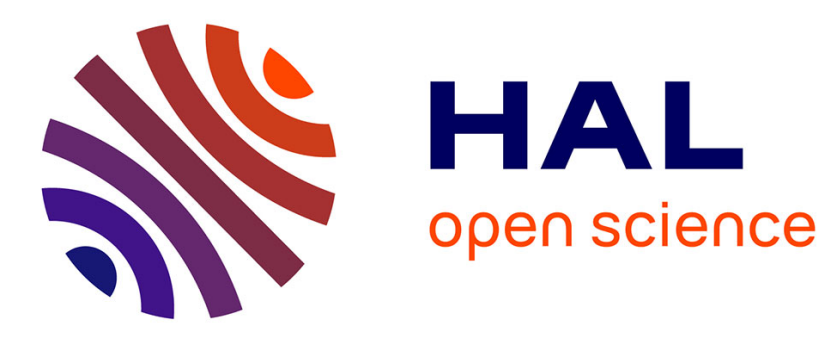

\title{
First Evaluation of Land Surface Emissivity Spectra Simulated with the Sail-Thermique Model
}

Albert Olioso, Frédéric Jacob, Marie Weiss

\section{To cite this version:}

Albert Olioso, Frédéric Jacob, Marie Weiss. First Evaluation of Land Surface Emissivity Spectra Simulated with the Sail-Thermique Model. 38. IEEE International Geoscience and Remote Sensing Symposium (IGARSS), Institute of Electrical and Electronics Engineers (IEEE). USA., Jul 2018, Valencia, Spain. pp.3951 - 3954, 10.1109/IGARSS.2018.8519436 . hal-02736994

\section{HAL Id: hal-02736994 \\ https://hal.inrae.fr/hal-02736994}

Submitted on 16 Nov 2021

HAL is a multi-disciplinary open access archive for the deposit and dissemination of scientific research documents, whether they are published or not. The documents may come from teaching and research institutions in France or abroad, or from public or private research centers.
L'archive ouverte pluridisciplinaire HAL, est destinée au dépôt et à la diffusion de documents scientifiques de niveau recherche, publiés ou non, émanant des établissements d'enseignement et de recherche français ou étrangers, des laboratoires publics ou privés. 


\title{
IRST EVALUATION OF LAND SURFACE EMISSIVITY SPECTRA SIMULATED WITH THE SAIL- THERMIQUE MODEL
}

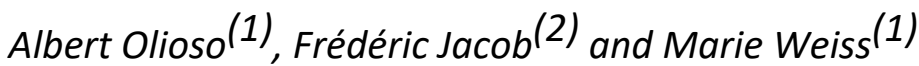

(1) UMR EMMAH, INRA-Université d'Avignon et des Pays de Vaucluse, Avignon, France (2) UMR LISAH, IRD-INRA-SUPAGRO, Montpellier, France (correspondance to albert.olioso@inra.fr)

\section{ABSTRACT}

The SAIL-Thermique model was developed to simulate land surface emissivity. It is adapted from the original SAIL model. A specific experiment was set-up over a soybean canopy for evaluating spectral emissivity simulations. Multispectral data were obtained thanks to a CIMEL CE 312-2 radiometer and emissivities calculated using the TES method. Comparison of multispectral emissivity simulations and measurements at various leaf area index levels were comparable in terms of emissivity values and spectral behavior.

Index Terms: Emissivity, thermal infrared, radiative transfer model, vegetation canopy, SAILThermique

\section{INTRODUCTION}

Spectral Land Surface Emissivity (LSE) is required for deriving surface temperature from thermal infrared (TIR) radiances as acquired by space sensors such as MODIS, ASTER or the sensors on board of the LANDSAT platforms. Surface temperature is an essential input to surface energy balance analysis, for example to map evapotranspiration [1][2][3][4]. The determination of emissivity from remote sensing data is not straightforward, while accurate values are required for surface temperature estimation procedures. [5] showed that an error of +/- 0.01 in spectral emissivity resulted in surface temperature error between $0.5 \mathrm{~K}$ and $1 \mathrm{~K}$ depending on the atmospheric conditions and the temperature level.

It is recognized that LSE varies according to many factors such as soil type, surface soil moisture and roughness, amount of vegetation cover and plant species. There is no exhaustive knowledge of the variations of LSE because in situ measurements of LSE are complex to implement. There are also only very few modelling studies [6] [7] [8] and almost no evaluation of LSE model against LSE measurements [9]. In this study we present the evaluation of multispectral simulation with the SAIL - Thermique model [6] of LSE against multispectral measurements over a soybean canopy. LSE measurements were performed using a multispectral radiometer and the TES method (see [10]).

\section{MATERIEL ET METHODE}

\subsection{The SAIL-Thermique model}

The SAIL model was originally developed by [11] for simulating bi-directional spectral reflectances in the solar domain. It was adapted for simulating radiative transfers in the 
thermal infrared, and particularly for simulating land surface emissivity by [1][6]. Considering the Kirchhoff's relation, the LSE in the direction of the measurement is calculated as the absorptivity of an incident directional radiation. Specific values of model parameters have to be prescribed including leaf reflectance, leaf transmittance, soil reflectance, Leaf Area Index (LAI) and Leaf Angle Distribution (LAD). The geometry of the measurement is set by considering a direction of observation equivalent to the direction of incident radiation (azimuth and zenith) and a diffuse fraction in the incident radiation set to zero.

A first evaluation of the model against broadband LSE data compiled from various databases was given by [9]. Compiled land surface emissivities for the 8-14 $\mu \mathrm{m}$ spectral band ranged between 0.92 and 0.99 . A root mean square error around 0.006 was obtained. When considering only herbaceous species, the root mean square error was 0.004 .

\subsection{Experimental setup}

An irrigated soybean crop was grown on the 'Flux and Remote Sensing' experimental site at INRA Avignon (South East France) during summer 2007. When the crop reached the flowering phenological stage it was almost fully covering the ground with a Leaf Area Index (LAI) close to 4 . A part of the crop $(10 \mathrm{~m} 2)$ was progressively thinned out in order to generate a spatial gradient of LAI from bare soil to maximum LAI value.

Radiances were measured at nadir using the multispectral TIR radiometer CIMEL Electronique CE 312-2 [12] in 5 channels equivalent to the channels of the ASTER sensor (on board of the TERRA platform) and one broad channel between 8 and $14 \mu \mathrm{m}$ (Table 1). The radiometer had a field of view of $10^{\circ}$. It was calibrated before the field measurements. The measurement in each channel lasts for around $20 \mathrm{~s}$, so that the full acquisition takes $2 \mathrm{~min}$. The measurements were performed in order to cover the full LAl gradient with around 10 measurements. Every two or three measurements, a set of measurements was performed over an Infragold reference plate in order to characterize atmospheric downwelling irradiance in each channel. The acquisitions were performed under cloudless sky starting half an hour after solar noon so that time variations in temperature were limited. The full measurement sequence was repeated 3 times in order to control the residual temperature variations.

\begin{tabular}{ccc}
\hline Channel & $\lambda_{\text {eff }}(\mu \mathrm{m})$ & $\Delta \lambda(\mu \mathrm{m})$ \\
\hline 1 & - & $8.01-13.34$ \\
2 & 11.296 & $10.86-11.71$ \\
3 & 10.567 & $10.16-10.96$ \\
4 & 9.145 & $8.95-9.34$ \\
5 & 8.676 & $8.49-8.86$ \\
6 & 8.420 & $8.25-8.60$ \\
\hline
\end{tabular}

Table 1. Effective wavelengths ( $\lambda$ eff) and full width at half- maximum $(\Delta \lambda)$ for the bands of the CE 312-2 radiometer ([10])

5.3. Emissivity calculation from radiance measurements 
Emissivities in the five ASTER channels were retrieved on the basis of the TemperatureEmissivity Separation (TES) algorithm proposed for ASTER by [13][14]. It can be applied to any multispectral sensors as far as at least 3 TIR channels are available [15]. The determination of emissivity requires additional information as radiances depends on surface temperature and emissivity. For a multispectral TIR sensor with $n$-channels, there are $n+1$ unknowns ( $n$ spectral emissivities plus one surface temperature) but only $\mathrm{n}$ available radiance measurements. TES uses the spectral contrast between the different channels to provide an additional equation that relates the minimum emissivity $\varepsilon$ min to the Maximum-Minimum Difference (MMD) calculated over the $\mathrm{n}$ channels. MMD is the ratio of the difference between the maximum and the minimum emissivity values ( $\varepsilon \max -\varepsilon \min$ ) to the mean emissivity value हmean. The equation that was derived empirically from laboratory measurements of spectra from rocks, soils, vegetation, snow and water samples by [13][14] is expressed as:

$\varepsilon_{\text {min }}=0.994-0.687\left(\frac{\varepsilon_{\text {max }}-\varepsilon_{\text {min }}}{\varepsilon_{\text {mean }}}\right)^{0.737}$

The TES algorithm requires the sky irradiance in each channel in order to account for the reflected radiation. We used the average of the two closest sky irradiance measurements obtained over the reference plate before and after each radiance measurements over the soybean canopy.

\subsection{Simulations}

Simulations of LSE with the SAIL-Thermique model were done by considering similar conditions as the experimental conditions. LAI was varied between 0 and 4 and the LAD set to planophile. Leaf reflectance spectrum (Figure 1) was obtained from measurements done using a SOC400T portable FTIR reflectometer [16] on soybean leaves harvested in the experimental field (3 leaf samples). An experimental protocol similar to [17] was used. Leaf transmittance was assumed equal to zero as [18] showed that leaf transmittance is usually very low for fresh herbaceous plant leaves. Soil reflectance spectra (Figure 1) were obtained on soil samples from the experimental field by [19]. LSE in the five radiometer channels were obtained by convoluting simulated LSE spectra by the spectral response function of each channel. Simulated emissivities were eventually compared to measured emissivities by considering measurements obtained over LAl close to the one used for the simulation. 


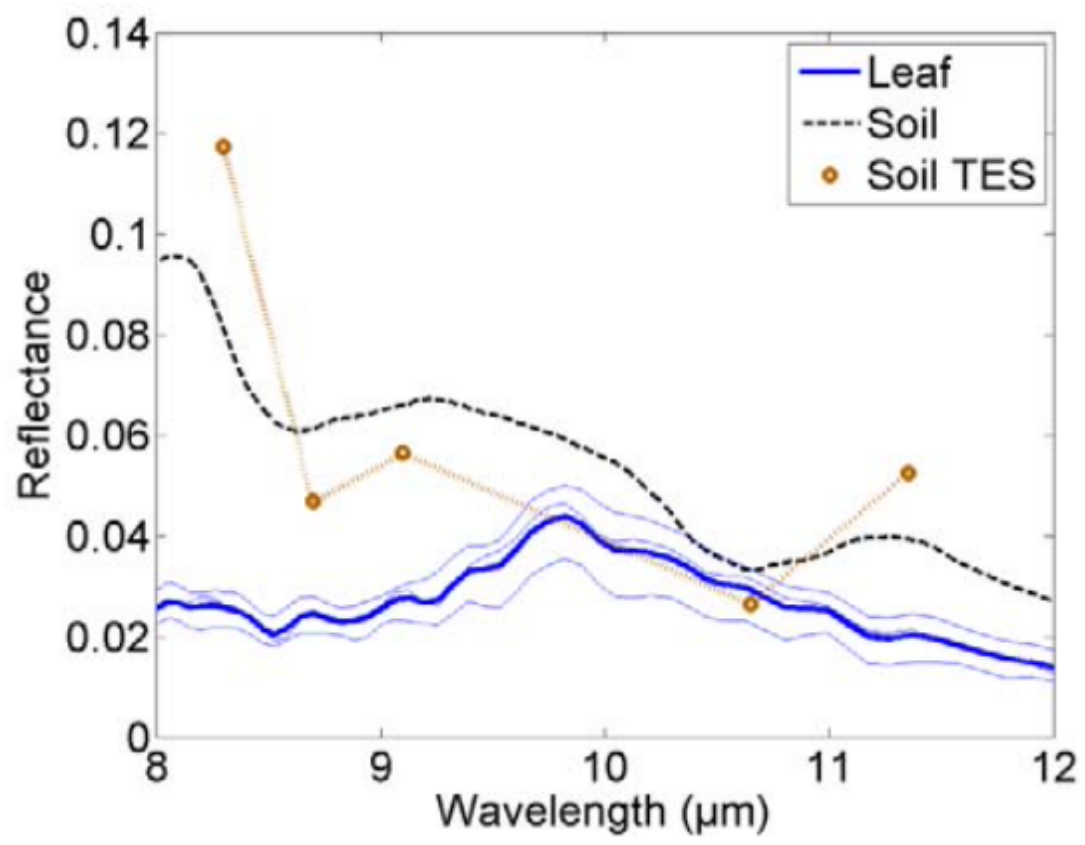

Figure 1. Soybean leaf (mean and 3 samples) and soil reflectance spectra acquired in Avignon, together with the soil reflectances derived in the CE 312-2 channels from TES emissivity estimates.

\section{RESULTS AND DISCUSSION}

Soil reflectances retrieved using TES were slightly different from the values obtained in the laboratory by [19] over soil samples (Figure 1). However, the differences were not too large as compared to other studies (e.g. [10]) and the spectral behavior was globally respected. The difference might be explained by several factors as spatial variations in soil composition, differences in soil aspect between laboratory measurements (powder), and/or uncertainties associated to the TES method.

Simulations of LSE spectra at LAI 0.125, 0.25, 0.5, 1, 2 and 4 are presented in Figure 2 and the simulated values obtained in the five radiometer channels in Figure 3 . These last simulations were performed assuming soil reflectance equivalent to the measurements obtained over bare soil with TES. Figure 4 shows the LSE obtained from the CIMEL measurements and the TES method over the in situ LAI gradient ( 10 points with LAI increasing from 0 to 4 ). 


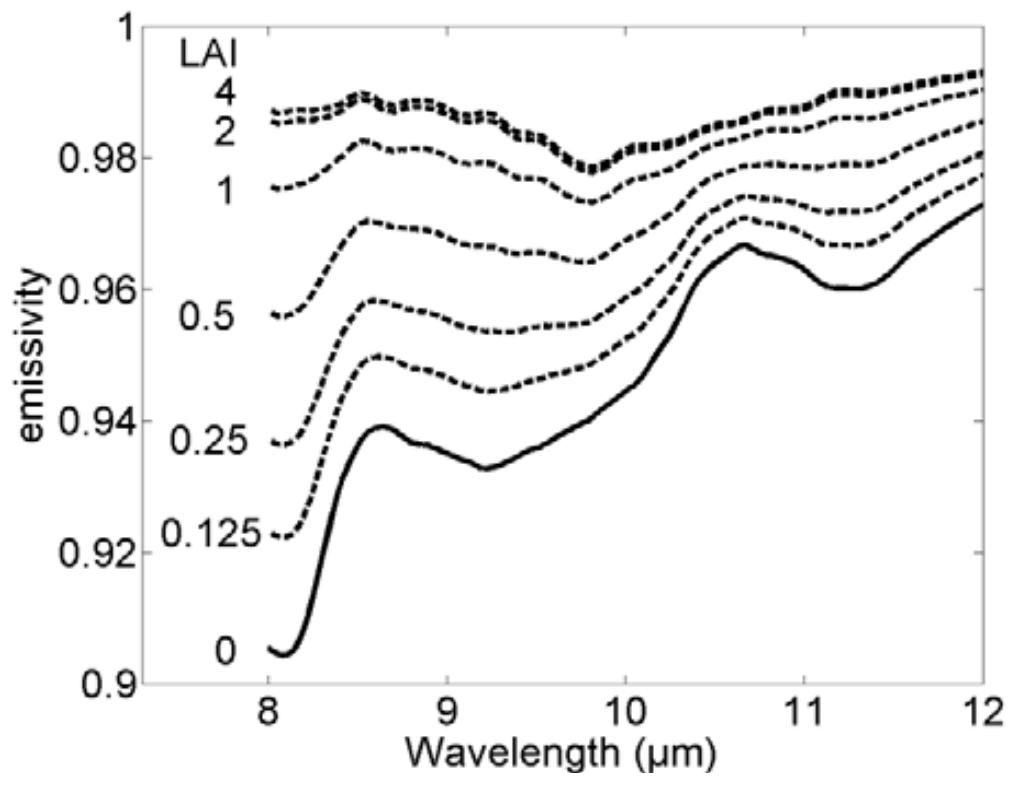

Figure 2. LSE spectra between 8 and $14 \mu \mathrm{m}$ simulated with SAIL-Thermique at LAI values of $0,0.125,0.25,0.5,1,2$ and 4 .

Spectra simulations in Fig. 2 show a rapid increase with LAI from bare soil values to saturation values obtained for LAl about 2 or 3 . This is in general agreement with previous modelling [6][7][8][9] and experimental [20][21] studies. Spectra at LAl above 2 present features in accordance with soybean leaf spectra (e.g., leaf reflectance bump at $9.85 \mu \mathrm{m}$ resulting in emissivity decrease) with no more visible impact of soil spectra features (e.g. soil absorption peak at $10.7 \mu \mathrm{m}$ and high soil reflectivity at $8.2 \mu \mathrm{m})$.

When considering simulated LSE in the radiometer channels (Fig 3.), the saturation of LSE at the higher LAI is of course still visible, but spectral features appeared only partially. The spectral behavior of soil surface is well captured by the 5 channels: impact of high soil reflectance in the first channel at $8.4 \mu \mathrm{m}$; local minimum values at $9.1 \mu \mathrm{m}$ and $11.3 \mu \mathrm{m}$; higher values at $8.7 \mu \mathrm{m}$ and $10.6 \mu \mathrm{m}$. Conversely, the main spectral feature of vegetation, around $9.9 \mu \mathrm{m}$ is not seen as no channel covers this part of the spectra.

Simulations show a general agreement with LSE measurements (comparing Figures 3 and 4). The spectral behavior related to soil and vegetation properties is globally similar even if TES estimates appeared more variable and slightly higher than SAIL-Thermique simulations (e.g., see saturated values between 0.985 and 0.990 in the simulation and between 0.990 and 0.992 in the TES estimates). This may be related to the uncertainties related to the TES methods and its application to the CIMEL Electronique CE 312-2 radiometer. The sensitivity analysis performed in [10] showed that the uncertainty in TES results may be larger than 0.01 while the uncertainties related to the non- simultaneity of the measurements in each channel was

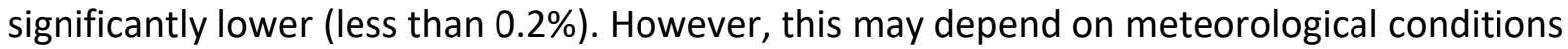
at the time of the measurements. The difference between simulations and measurements may be also related to the representativity of the leaf reflectance spectrum used for the 
simulation (average of only 3 leaf samples with a standard deviation close to 0.005). Model hypothesis as considering isothermal and homogeneous plant canopies may also be in cause.

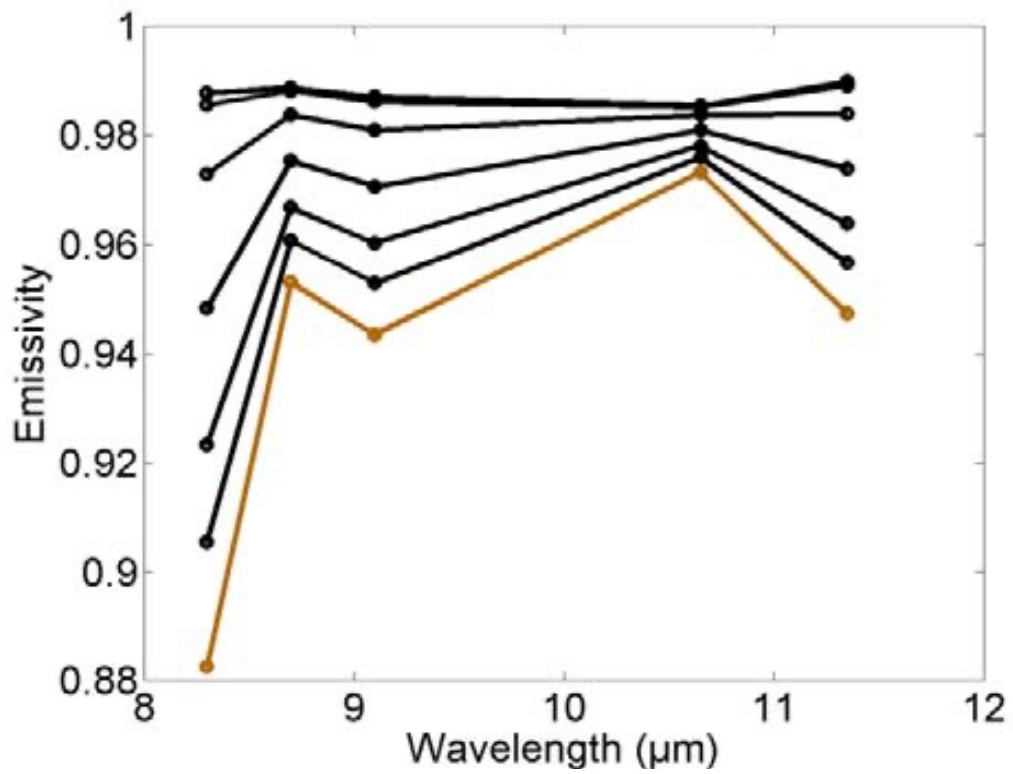

Figure 3. LSE in the 5 radiometer channels simulated with SAIL- Thermique at LAI values of 0 , $0.125,0.25,0.5,1,2$ and 4 . LSE values are given at the central wavelength of each channel.

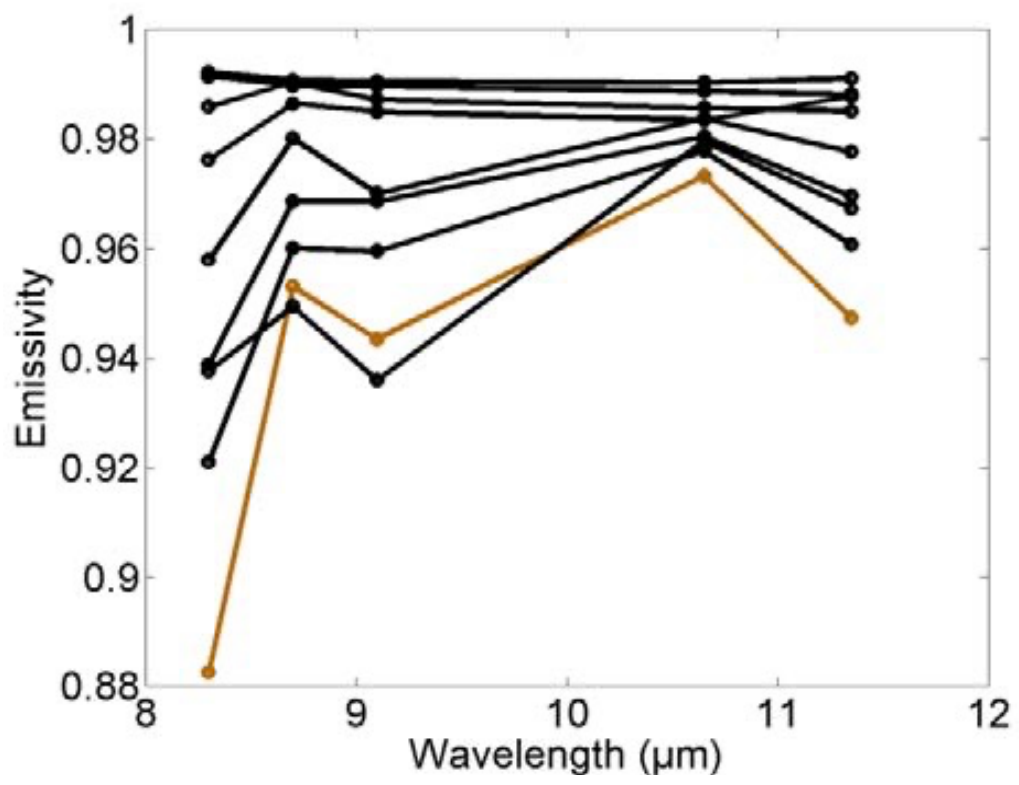

Figure 4. LSE obtained from the application of the TES method to the radiance measurements in the 5 radiometer channels. LSE values are given at the central wavelength of each channel. Each line corresponds to measurements obtained at specific position over the 0 to 4 LAl gradient. 


\section{CONCLUSION}

We presented a preliminary evaluation of multispectral simulations of emissivity with the SAIL-Thermique model. The results are encouraging as simulations are globally in agreement with the measurements. However, we still have to provide a more exhaustive evaluation, including numerical evaluation of the differences between simulations and measurements, over a larger number of situations and plant canopies. We also have to keep in mind that emissivity simulations considered isothermal canopies while the variation of temperature within plant canopies can be large and can generate large directional effects [22][23].

\section{ACKNOWLEDGEMENT}

This work was made possible thanks to the financial support of CNES (Centre National d'Etudes Spatiales) through the TOSCA program (EVASPA v3.0 and E2IRT) and of PNTS (Programme National de Télédétection Spatiale) program (contract 06CV101, Potentialité des mesures ASTER pour l'estimation de la température de surface).

\section{REFERENCES}

[1] A. Olioso, H. Chauki, D. Courault, and J.-P. Wigneron, "Estimation of evapotranspiration and photosynthesis by assimilation of remote sensing data into SVAT models", Rem. Sens. Environ., 68, pp. 341-356, 1999.

[2] M.C. Anderson, R.G. Allen, A. Morse, and W.P. Kustas, "Use of Landsat thermal imagery in monitoring evapotranspiration and managing water resources", Rem. Sens. Environ., 122, pp. 50-65, 2012.

[3] B. Gallego-Elvira, A. Olioso, M. Mira, S. Reyes-Castillo, G. Boulet, O. Marloie, S. Garrigues, D. Courault, M. Weiss, P. Chauvelon, and O. Boutron, "EVASPA (EVapotranspiration Assessment from SPAce) tool: An overview", Proc. Environ. Sci., 19, pp. 303-310, 2013.

[4]J.-P. Lagouarde, and G. Boulet, "Energy Balance of Continental Surfaces and the Use of Surface Temperature", Chapter 10, pp. 323 - 362. In:Land Surface Remote Sensing in Continental Hydrology, N. Baghdadi, and M. Zribi Eds., ISTE Editions, ISBN : 9781785481048, 2016.

[5] A. Olioso, "Estimating the difference between brightness and surface temperatures for a vegetal canopy", Agric. Forest Meteor., 72, pp. 237-242, 1995.

[6] A. Olioso, "Simulating the relationship between thermal emissivity and the normalized difference vegetation index," Int. J. Remote Sens., 16, pp. 3211-3216, 1995.

[7] Y .A. Anton, and Y .K. Ross, "Emissivity of a vegetation-soil system," Sov. J. Remote Sens., 7, pp. 859-869, 1990.

[8] W. Verhoef, L. Jia, Q. Xiao, and Z. Su, "Unified Optical- Thermal Four-Stream Radiative Transfer Theory for Homogeneous Vegetation Canopies", IEEE Trans. Geos. Remote Sens., 45, pp. 1808-1822, 2007. 
[9] A. Olioso, F. Jacob, and A. Lesaignoux, "SAIL-thermique, a model to simulate land surface emissivity (LSE) spectra". 1st International Surface Working Group, 19-20 July 2017, Monterey, California. 2017.

[10] M. Mira, T.J. Schmugge, E. Valor, V. Caselles, and C. Coll, "Comparison of Thermal Infrared Emissivities Retrieved With the Two-Lid Box and the TES Methods With Laboratory Spectra", IEEE Trans. Geosci. Remote Sensing, 47, pp. 1012-1021, 2009.

[11] W. Verhoef, "Light scattering by leaf layers with application to canopy reflectance modeling: The SAIL model," Remote Sens. Environ., 16, pp. 125-141, 1984.

[12] G. Brogniez, C. Pietras, M. Legrand, P. Dubuisson, and M. Haeffelin, "A high-accuracy multiwavelength radiometer for in situ measurements in the thermal infrared. Part II: Behavior in field experiments," J. Atmos. Ocean Technol., 20, pp. 1023-1033, 2003.

[13] A. Gillespie, S. Rokugawa, T. Matsunaga, J.S. Cothern, S. Hook, and A. Kahle, "A temperature and emissivity separation algorithm for Advanced Spaceborne Thermal Emission and Reflection Radiometer (ASTER) images," IEEE Trans. Geosci. Remote Sensing, 36, pp. 1113-1126, 1998.

[14] T. J. Schmugge, S. J. Hook, and C. Coll, "Recovering surface temperature and emissivity from thermal infrared multispectral data," Remote Sens. Environ., 65, pp. 121-131, 1998.

[15] F. Jacob, A. Lesaignoux, A. Olioso, M. Weiss, K. Caillault, S. Jacquemoud, F. Nerry, A. French, T. Schmugge, X. Briottet, and J.-P. Lagouarde, "Reassessment of the temperature - emissivity separation from multispectral thermal infrared data: Introducing the impact of vegetation canopy by simulating the cavity effect with the SAIL-Thermique model," Rem. Sens. Environ., 198, pp. 160-172, 2017.

[16] D.A. Jaworske, and T.J. Skowronski, "Portable Infrared Reflectometer for Evaluating Emittance," Proceedings of the Space Technology and Applications International Forum (STAIF) 2000, Albuquerque, NM, pp. 791-796, February 2000.

[17] S. Fabre, A. Lesaignoux, A. Olioso, and X. Briottet, "Influence of water content on spectral reflectance of leaves in the in the $0.4-15 \mu \mathrm{m}$ domain," IEEE Geosc. Remote Sens. Let., 8, pp. 143-147, 2011.

[18] F. Gerber, R. Marion, A. Olioso, S. Jacquemoud, B. Ribeiro da Luz, and S. Fabre, "Modeling directional-hemispherical reflectance and transmittance of fresh and dry leaves from 0.4 $\mu \mathrm{m}$ to $5.7 \mu \mathrm{m}$ with the PROSPECT-VISIR model," Rem. Sens. Environ., 115, pp. 404-414, 2011.

[19] A. Lesaignoux, S. Fabre, and X. Briottet, "Influence of soil moisture content on spectral reflectance of bare soils in the 0.4-14 $\mu \mathrm{m}$ domain," Int. J. Remote Sens., 34, pp. 22682285, 2013.

[20] A.A. van de Griend, and M. Owe, "On the relationship between thermal emissivity and the normalized difference vegetation index for natural surfaces," Int. J. Remote Sens., 14, pp. 1119-1131, 1993.

[21] M. Mira, A. Olioso, B. Gallego-Elvira, D. Courault, S. Garrigues, O. Marloie, O. Hagolle, P. Guillevic, G. Boulet, "Uncertainty assessment of surface net radiation derived from Landsat images," Rem. Sens. Environ., 175, pp. 251-270, 2016.

[22] D. Luquet, A. Vidal, J. Dauzat, A. Bégué, A. Olioso, and P. Clouvel, "Using directional TIR measurements and $3 \mathrm{D}$ simulations to assess the limitations and opportunities of water stress indices," Remote Sens. Environ., 90, pp. 53-62, 2004.

[23] C. Duffour, A. Olioso, J. Demarty, C. Van der Tol, and J.-P. Lagouarde, "An evaluation of SCOPE: a tool to simulate the directional anisotropy of satellite-measured surface temperatures," Rem. Sens. Environ., 158, pp. 362-375, 2015. 